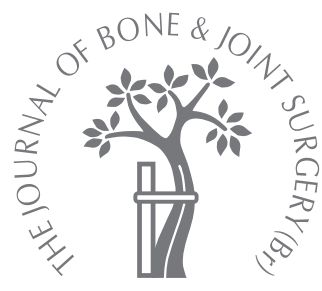

- CASE REPORT

\title{
Traumatic transepiphyseal separation of the upper femoral epiphysis following seizures in two children with cerebral palsy
}

M. S. Ballal,

A. Dawoodi, J. Sampath, A. Bass

From The Royal Liverpool Children's NHS Trust, Liverpool, England
M. S. Ballal, MBBS,

MRCSEd, Senior House Officer A. Dawoodi, MBBS, MRCSEd, Senior House Officer II. Sampath, FRCS (Tr \& Orth), Consultant Orthopaedic Surgeon

A. Bass, FRCS (Tr \& Orth), Consultant Orthopaedic

Surgeon

Department of Paediatric

Orthopaedics

The Royal Liverpool Children's NHS Trust, Alder Hey, Eaton Road, Liverpool L12 2AP, UK.

Correspondence should be sent to Mr M. S. Ballal; email: dr_moez@yahoo.co.uk

(C)2008 British Editorial Society of Bone and Joint Surgery doi:10.1302/0301-620X.90B3. $20049 \$ 2.00$

$J$ Bone Joint Surg $[\mathrm{Br}]$ 2008;90-B:382-4.

Received 6 August 2007;

Accepted after revision 19

November 2007

\begin{abstract}
Transepiphyseal separation of the neck of the femur following grand mal seizures is described in two children with cerebral palsy. Closed reduction and percutaneous fixation was followed by a period in a hip spica. Although the incidence of avascular necrosis of the femoral head is high following such injury, this has not occurred in these patients at a follow-up of 18 months.
\end{abstract}

A fracture of the proximal femur with transepiphyseal separation with or without dislocation of the femoral head from the acetabulum is a rare fracture of the hip in children. ${ }^{1}$ According to the classification of Delbet and Colonna ${ }^{2}$ this is a type 1 fracture. A high incidence of avascular necrosis (AVN) of the femoral head has been reported with injuries of this nature in children. ${ }^{3-5}$ Previous reports described it occurring following significant trauma. ${ }^{6-11}$ To our knowledge, there are no reported cases of type I fractures following seizures. We describe two cases of this condition which occurred after seizures in patients with total body involvement with cerebral palsy.

\section{Case reports}

Case 1. A 22-month-old female child with migrating partial epilepsy of infancy and severe developmental delay also suffered from generalised tonic/clonic fits on an almost daily basis. The seizures were permitted to settle spontaneously and the child received oral anti-epileptic medication. She was unable to communicate or walk but did not have any hormonal disturbance.

After one generalised tonic/clonic fit she remained restless and maintained her right leg in an awkward position. She was assessed at her local hospital the same day where a radiograph showed a transepiphyseal separation of the neck of the right femur (Fig. 1a).

She was referred to our hospital and the following day underwent closed reduction and percutaneous fixation with two $2.5 \mathrm{~mm}$ Kirschner wires (Fig. 1b). A hip spica was applied which was worn for six weeks, when the spica and pins were removed (Fig. 1c). Her follow- up was unremarkable and at 12 months there was no sign of AVN of the femoral head. Thereafter, she was reviewed at her local hospital because of social circumstances and radiographs taken at 18 months follow-up did not show any signs of AVN.

Case 2. A nine-year-old boy with trigonocephaly, grand mal seizures, quadriplegic cerebral palsy and an abnormality of chromosomes 9 and 13 was brought to the accident and emergency department following two grand mal seizures. He was unable to communicate or walk and received oral medication for the control of epilepsy. His parents had noticed a deformity affecting the right leg. Radiographs revealed a transepiphyseal fracture of the left proximal femur and a subtrochanteric fracture of the right femur distal to a plate which had been inserted three years previously following a fracture (Figs $2 \mathrm{a}$ and $2 \mathrm{~b}$ ).

He underwent closed reduction and percutaneous fixation with a single $4.5 \mathrm{~mm} \mathrm{AO}$ partially-threaded cancellous screw to the left hip. The internal fixation was removed from the right femur to permit open reduction and internal fixation of the new fracture with a blade plate.

A hip spica was applied for six weeks after which the hips were left free. He was reviewed at six-monthly intervals and at 18 months there was no radiological evidence of AVN (Fig. 2c). He continues to be followed up.

\section{Discussion}

Fractures of the femoral neck in children are rare. ${ }^{12-19}$ Their complications may lead to lifelong disability especially where AVN occurs. ${ }^{20}$ Standardisation of treatment is difficult because of the variability of presentation of 


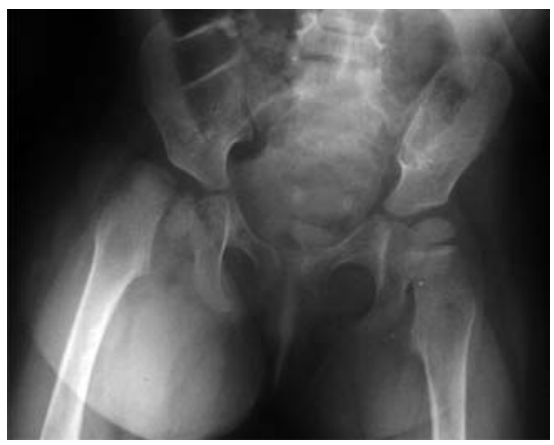

Fig. 1a

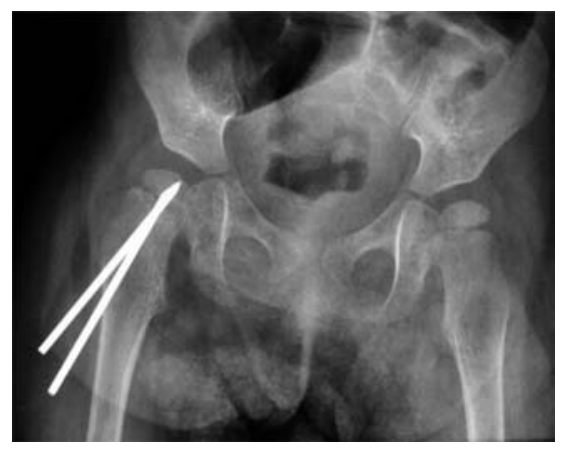

Fig. $1 b$

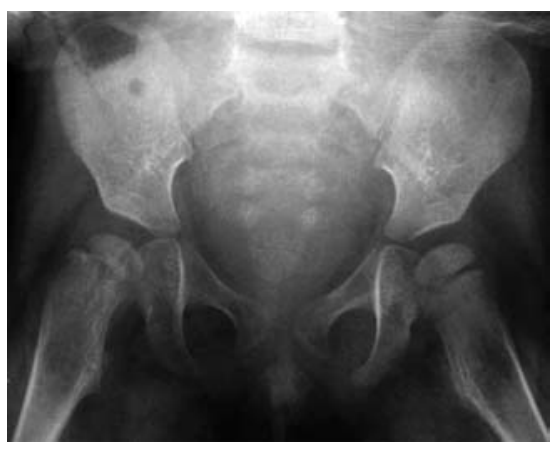

Fig. 1c

Anteroposterior radiographs of the pelvis showing a) transepiphyseal separation of the right upper femoral epiphysis, b) fixation with two Kirschner wires, and c) follow-up appearances at one year after removal of fixation showing healing of the former separation.

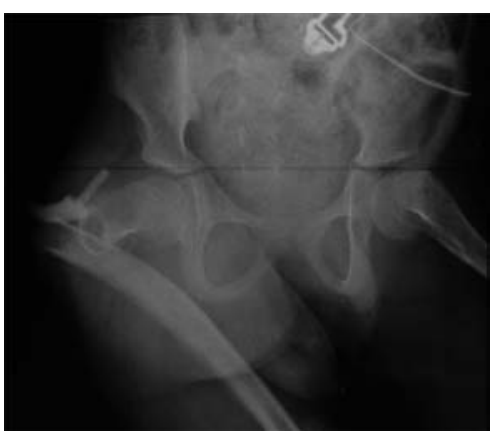

Fig. $2 a$

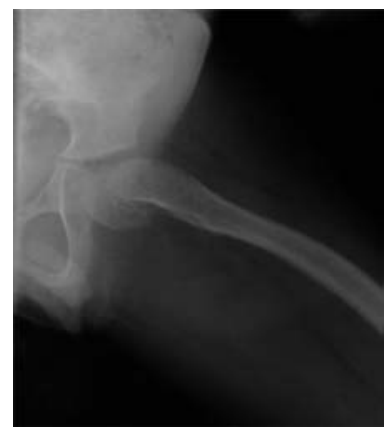

Fig. $2 b$

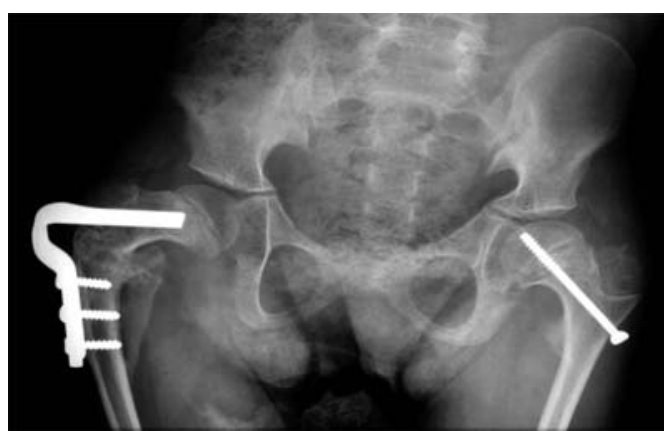

Fig. 2c

a) Anteroposterior radiograph of the pelvis and b) lateral of the left hip, showing a right sub-trochanteric femoral fracture at the level of previous internal fixation and transepiphyseal separation of the left upper femoral epiphysis. c) A one year follow-up radiograph showing fixation with a blade plate of the right femur and a single $A O$ cannulated screw inserted in the left femur. Both fractures have united.

these fractures and a lack of agreement concerning the aetiology and management of the complications that can accompany them. ${ }^{21}$

The incidence of AVN following fractures of the femoral neck in children has been reported to range between $0 \%$ and $92 \%,{ }^{8,22-24}$ Other authors reported an incidence between $80 \%$ and $100 \%$ following Delbet and Colonna type I fractures. ${ }^{3-5}$ The type of fracture, the extent of the displacement, the age of the patient, and the treatment conducted are all strong independent predictors for the development of AVN. ${ }^{24}$ High rates of other complications such as premature closure of the physis, nonunion and a poor outcome have also been reported despite early open reduction and fixation. ${ }^{2,3,8,10}$

Damage to the epiphyseal blood supply at the time of the injury seems to be the main factor in the development of AVN. Ng and Cole ${ }^{25}$ suggested that kinking and tamponade of the vessels did not contribute significantly to the development of AVN in this type of fracture. They felt that the necrosis was as a result of immediate, irreversible changes in the blood supply of the femoral head at the time of injury. Trueta ${ }^{26}$ stated that the poor prognosis of this injury is related to disruption of the lateral epiphyseal blood vessels which form the main blood supply to the epiphysis.

As significant trauma is the most common reported cause of separation of the upper femoral epiphysis, ${ }^{6-11}$ we believe this is the first report of such injury occurring following seizure.

No benefits in any form have been received or will be received from a commercial party related directly or indirectly to the subject of this article.

\section{References}

1. Ingram AJ, Bachynski B. Fractures of the hip in children. J Bone Joint Surg [Am] 1953;35-A:867-87.

2. Colonna PC. Fractures of the neck of the femur in children. Am J Surg 1929;6:793-7.

3. Canale ST, Bourland WL. Fracture of the neck and intertrochanteric region of the femur in children. J Bone Joint Surg [Am] 1977;59-A:431-43.

4. Werkman DM. The transepiphyseal fracture of the femoral neck. Injury 1980;12:50-2. 
5. Barquet A. Avascular necrosis following traumatic hip dislocation in childhood: factors of influence. Acta Orthop Scand 1982;53:809-13.

6. Bombaci H, Centel T, Babay A, Türkmen M. Evaluation of complications of femoral neck fractures in children operated on at least 24 hours after initial trauma. Acta Orthop Traumatol Turc 2006;40:6-14 (in Turkish).

7. Aminudin CA, Suhail A, Shukur MH, Yea JK. Transphyseal fracture-separation of the femoral capital epiphysis: a true SCFE of traumatic origin. Med J Malaysia 2006;61(Supp A):94-6.

8. Ratliff AH. Fractures of the neck of the femur in children. J Bone Joint Surg [Br]1962;44B:528-42.

9. Akahane T, Fujioka F, Shiozawa R. A transepiphyseal fracture of the proximal femur combined with a fracture of the mid-shaft of ipsilateral femur in a child: a case report and literature review. Arch Orthop Trauma Surg 2006;126:330-4.

10. Fiddian NJ, Grace DL. Traumatic dislocation of the hip in adolescence with separation of the capital epiphysis: two case reports. J Bone Joint Surg [Br]1983;65-B:148-9.

11. Mohammad S, Port A, Montgomery RJ. Transepiphyseal fracture of the femoral neck with dislocation of the femoral head and fracture of the posterior column of the acetabulum in a child. J Bone Joint Surg [Br]2002;84-B:113-15.

12. Morsy HA. Complications of fracture of the neck of the femur in children: a long-term follow-up study. Injury 2001;32:45-51

13. Chládek P, Trc T. Fractures of the femoral neck in children: complications and their treatment. Acta Chir Orthop Traumatol Cech 2002;69:31-4.

14. Cheng JC, Tang N. Decompression and stable internal fixation of femoral neck fractures in children can affect the outcome. J Pediatr Orthop 1999:19:338-43.

15. Davison BL, Weinstein SL. Hip fractures in children: a long-term follow-up study. $J$ Pediatr Orthop 1992;12:355-8
16. Sferopoulos NK, Papavasiliou VA. 'Natural' healing of hip fractures in childhood. Injury 1994;25:493-6.

17. Mirdad T. Fractures of the neck of femur in children: an experience at the Aseer Central Hospital, Abha, Saudi Arabia. Injury 2002;33:823-7.

18. Abramovic M, Brdar R, Vidosavlijevic M. Orthopedic reduction and percutaneous fixation of femoral neck fractures in children. Srp Arh Celok Lek 2004;132(Suppl 1):72 6 (in Serbian).

19. Togrul E, Bayram H, Gulsen M, Kalaci A, Ozbarlas S. Fractures of the femora neck in children: long-term follow-up in 62 hip fractures. Injury 2005;36:123-30.

20. Magu NK, Singh R, Sharma AK, Ummat V. Modified Pauwel's intertrochanteric osteotomy in neglected femoral neck fractures in children: a report of 10 cases followed for a minimum of 5 years. J Orthop Trauma 2007;21:237-43.

21. Azouz EM, Karamitsos C, Reed MH, et al. Types and complications of femoral neck fractures in children. Pediatr Radiol 1993;23:415-20.

22. Forlin E, Guille JT, Kumar SJ, Rhee KJ. Complications associated with fracture of the neck of the femur in children. J Pediatr Orthop 1992:12:503-9.

23. Morissy R. Hip fractures in children. Clin Orthop 1980;152:202-10.

24. Moon ES, MehIman CT. Risk factors for avascular necrosis after femoral neck fractures in children: 25 Cincinnati cases and meta-analysis of 360 cases. J Orthop Trauma 2006:20:323-9.

25. Ng GP, Cole WG. Effect of early decompression on the frequency of avascular necrosis in children with fractures of the neck of the femur. Injury 1996;27:419-21.

26. Trueta J. The normal vascular anatomy of the human femoral head during growth. $J$ Bone Joint Surg [Br] 1957;39-B:358-94. 